\title{
The Effect of Vehicle on the Tissue Distribution Profiles of Radioiodinated Cholesterol Esters in the Rat
}

\author{
N. Korn, G. D. Nordblom and R. E. Counsell* \\ Department of Pharmacology, The University of Michigan Medical School, \\ Ann Arbor, Michigan 48109, U.S.A.
}

(Received 20 August 1980)

\begin{abstract}
Several groups have examined the possible use of radioiodinated cholesterol esters to achieve selective uptake of radioactivity in the adrenal cortex and have obtained variable results. This study indicates that the tissue distribution profile varies not only with the type of ester, but also with the vehicle employed for administration. Radioiodinated 19-iodocholesterol (125-IC), iodocholesteryl palmitate (125-ICP) and iodocholesteryl oleate (125-ICO) were dissolved in either tween vehicle (saline containing $1.6 \%$ tween 80 and $10 \%$ ethanol) or myristate vehicle (isopropyl myristateethanol, $1: 5 \mathrm{v} / \mathrm{v}$ ) and administered i.v. to rats. Irrespective of the agent, considerably more radioactivity appeared in the target organs when the tween vehicle was employed. When the myristate vehicle was used, higher levels of radioactivity appeared in the lung. This finding suggests precipitation of the agents from the myristate vehicle occurred upon administration. In the tween vehicle, 125-ICO showed almost three times greater predilection for adrenal cortex than 125-ICP with levels of activity approaching those seen for 125-IC. Adrenal activity and adrenal to non-target ratios were sufficient for visualization of the adrenals at 5 days after injection of 125-ICO in the tween vehicle. Lipid extraction and TLC analysis of tissue radioactivity revealed that radioactivity in the adrenal and ovary was predominantly in an esterified form. Further analysis of the esters present after injection of 125-ICP showed these to be a mixture of mono and polyunsaturated esters. The site of hydrolysis and subsequent reesterification is an interesting biochemical aspect that remains to be elucidated.
\end{abstract}

\section{Introduction}

RADIOIODINATED derivatives of cholesterol have been used successfully to image the adrenal gland and related tumors. Since cholesterol is present in the circulation predominantly in an esterified form, several groups have examined the possible use of radioiodinated cholesterol esters to achieve selective uptake of radioactivity in the adrenal cortex with variable results. A previous report from this laboratory ${ }^{(1)}$ suggested that in contrast to 19-radioiodinated cholesterol which showed selective concentration in the adrenal cortex following various routes of administration, esters of 19-radioiodinated cholesterol (acetate and palmitate) produced high concentrations of radioactivity in the adrenal only after oral administration. A preliminary experiment with 19-radioiodinated cholesteryl oleate, however, resulted in selective accumulation of activity in the adrenal gland. This result, as well as a recent report ${ }^{(2)}$ showing selective adrenal uptake after administration of radioiodinated cholesterol esters prompted a re-examination of 19-radioiodinated cholesterol esters as organ or tumor-imaging agents for the adrenal cortex.

\section{Materials and Methods}

Radioiodinated 19-iodocholesterol (125-IC), 19-iodocholesteryl palmitate (125-ICP) and 19-iodocholesteryl oleate $(125-\mathrm{ICO})$ were prepared as previously described. ${ }^{(1.3)}$ The

\footnotetext{
* To whom reprint requests should be sent.
} 
compounds were formulated for injection by dissolving in either tween vehicle $(1.6 \%$ tween 80 and $10 \%$ ethanol in saline) or myristate vehicle (isopropyl myristate-ethanol, $1: 5 \mathrm{v} / \mathrm{v}$ ). Prior to use, radiochemical purity of each compound was determined by thinlayer chromatography (TLC) using silica gel plates (Eastman Kodak) developed in benzeneethyl acetate, 9:1 v/v (system 1) and/or carbon tetrachloride (system 2). In addition, aliquots of each solution were assayed in a well-scintillation counter* to determine the radioactive concentration of each solution.

\section{Tissue distribution studies}

Thirty female Sprague-Dawley rats $\dagger$ weighing $200-250 \mathrm{~g}$ were used as experimental animals. The rats were housed in temperature and light-controlled quarters and had free access to food $\ddagger$ and water. Prior to injection, the rats were monitored for stage of estrous cycle by vaginal smear. The rats were divided into six groups and each group received an i.v. injection of one of the following: $125-\mathrm{IC}\left(25.8 \mu \mathrm{Ci} 0.057 \mathrm{mg}^{-1}\right)$ in $0.25 \mathrm{ml}$ tween; 125-IC $\left(24.3 \mu \mathrm{Ci} 0.12 \mathrm{mg}^{-1}\right)$ in $0.10 \mathrm{ml}$ myristate; $125-\mathrm{ICP}\left(16.5 \mu \mathrm{Ci} 0.22 \mathrm{mg}^{-1}\right)$ in $0.30 \mathrm{ml}$ tween; 125 -ICP $\left(20.4 \mu \mathrm{Ci} 0.18 \mathrm{mg}^{-1}\right)$ in $0.15 \mathrm{ml}$ myristate; $125-\mathrm{ICO}\left(30.8 \mu \mathrm{Ci} 0.22 \mathrm{mg}^{-1}\right)$ in $0.25 \mathrm{ml}$ tween; or $125-\mathrm{ICO}\left(24.0 \mu \mathrm{Ci} 0.24 \mathrm{mg}^{-1}\right)$ in $0.10 \mathrm{ml}$ myristate. The rats were killed by exsanguination from the heart while under ether anesthesia at $24 \mathrm{~h}$ post injection. Samples of adrenal cortex, blood, liver, lung, ovary, spleen and thyroid were placed in tared cellulose acetate capsules and weighed. The samples were assayed for radioactivity in a well-scintillation counter for $10 \mathrm{~min}$ or until 40,000 counts had accummulated. Counting efficiency for ${ }^{125} \mathrm{I}$ was $84 \%$. In addition, samples of tissues were frozen for subsequent extraction studies.

\section{Adrenal scan}

A female Sprague-Dawley rat (211 g) was given an i.v. injection of $125-\mathrm{ICO}(123 \mu \mathrm{Ci}$ $0.88 \mathrm{mg}^{-1}$ ) in $1.0 \mathrm{ml}$ tween. At 1 and 5 days following administration, the rat was anesthetized by i.p. injection of $0.2 \mathrm{ml}$ sodium pentobarbital $\left(50 \mathrm{mg} \mathrm{ml}^{-1}\right)$. The rat was scanned in the prone position using a Berthold Radiochromatogram Scanner (LB2723) with small animal scanning attachments. After the 5 day scan, the rat was killed and selected tissues assayed for radioactivity as previously described.

\section{Extraction studies}

Extraction of tissue lipids was performed as previously described ${ }^{(4)}$ except that TLC analysis of the lower phase was performed on silica gel plates developed in solvent system 1 for all samples. In addition, samples from rats that received 125-ICP were also analyzed using solvent system 2 . Cholesterol and its palmitate, oleate, linoleate and arachidonate esters and 19-iodocholesterol and its palmitate, oleate and linoleate esters were chromatographed simultaneously and used as reference standards.

\section{Results and Discussion}

The results of tissue distribution studies with 125-IC and its palmitate and oleate esters administered in either tween or myristate have been summarized in Table 1. Irrespective of the agent administered, concentration of radioactivity in the adrenal cortex was greater when the tween vehicle was used as compared to the myristate vehicle. This difference was most noticeable when the oleate was administered (17 times greater) as compared to the palmitate ( 5 times greater) or the free sterol ( 2 times greater). A similar pattern was noted for activity in the ovary. Thyroid activity, generally considered to be an indicator of in vivo deiodination, was also much higher when the compounds were administered in the tween vehicle. Thus, the injection vehicle appeared to be an important factor in the distribution profiles of 125-IC esters and, to a lesser extent, 125-IC.

\footnotetext{
* Searle 1185 Automatic Gamma System.

† Spartan Research Animals Inc., Hasslett, MI.

$\ddagger$ Teklad $4 \%$ Rat and Mouse Diet.
} 


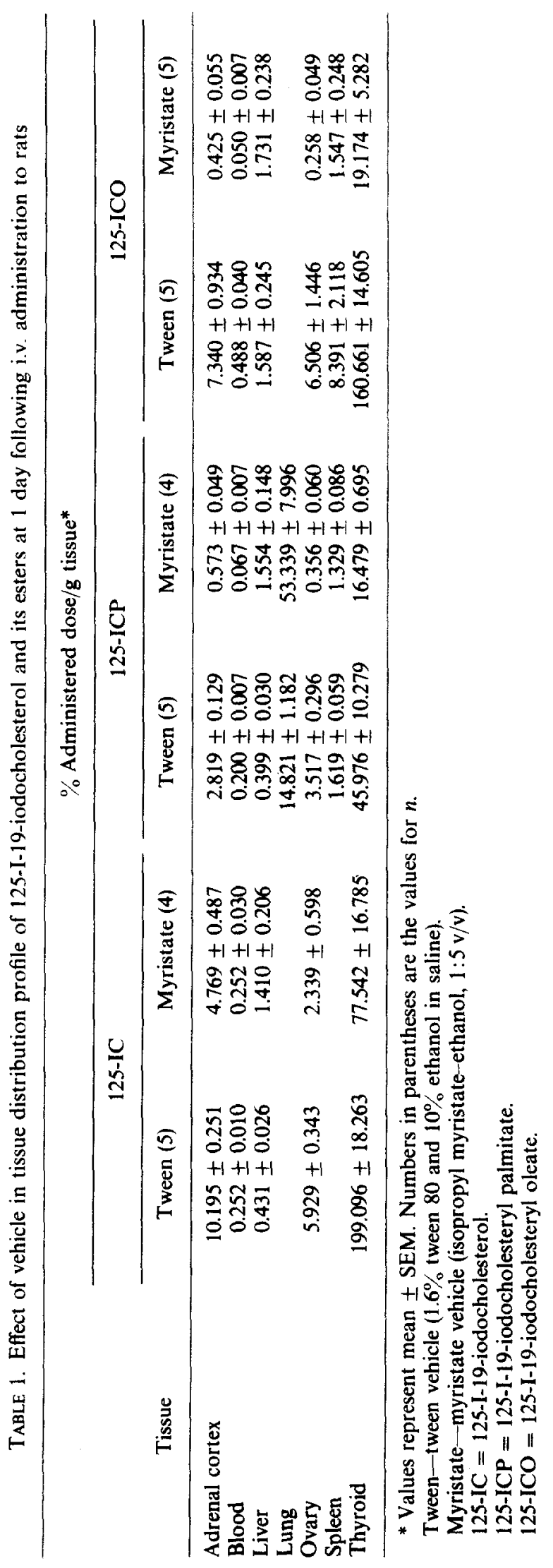


Irrespective of the vehicle, higher levels of radioactivity accumulated in the adrenal following administration of $125-\mathrm{IC}$ rather than the esterified forms.

In addition to vchicle, the ester portion of the molecule appeared to influence the tissue distribution profile of these agents. When the more appropriate tween vehicle was used for injection, tissue levels of radioactivity were consistently higher when 125-ICO was injected as compared to $125-\mathrm{ICP}$, and activity in the target tissues (adrenal cortex and ovary) was closer to that seen when the free sterol was administered. Although greater target radioactivity following administration of 125-ICO may be related to the oleate specificity reported for many metabolic processes (e.g. chylomicron specificity for oleate formation, liver soluble cholesterol esterase preference for oleate, liver specificity for oleate formation with oleate present as the major liver ester), other esters must be studied to confirm that oleate is the preferred ester. FUKUSHI et al..$^{(2)}$ however, have noted that adrenal levels of radioactivity following administration of radioiodinated cholesteryl acetate were also similar to radioiodinated cholesterol.

The results of extraction of lipid-soluble tissue radioactivity followed by TLC analysis of the extract have been summarized in Tables 2 and 3. Most of the radioactivity present in all tissues analyzed was extractable into the organic phase. Radioactivity which comigrated with both the free and esterified standards in system 1 was present in all tissue extracts. In the target tissues, adrenal and ovary, the greater percentage of activity was found to comigrate with the esterified standards. These results are in agreement with those previously reported for $125-\mathrm{IC}^{(4)}$ When the tissue extracts from rats that received 125-ICP were analyzed by TLC to separate esters by degree of saturation, most of the

TABLE 2. Results of TLC analysis of lipid-soluble radioactivity from tissue of rats that received 19-radioiodinated cholesterol esters

\begin{tabular}{|c|c|c|c|}
\hline \multirow{2}{*}{$\begin{array}{l}\text { Compound } \\
\text { and } \\
\text { tissue }\end{array}$} & \multirow{2}{*}{$\begin{array}{c}\% \text { of Tissue radioactivity } \\
\text { extracted into organic } \\
\text { phase* }\end{array}$} & \multicolumn{2}{|c|}{$\begin{array}{l}\text { TLC analysis of organic phasc } \\
\text { benzene-ethyl acetate }(9: 1 \mathrm{v} / \mathrm{v})^{*}\end{array}$} \\
\hline & & $\%$ Free & $\%$ Esterified \\
\hline \multicolumn{4}{|l|}{ 125-ICP Tween† } \\
\hline Adrenal cortex & $81.4 \pm 0.8$ & $14.7 \pm 2.6$ & $70.0 \pm 5.8$ \\
\hline Plasma & $70.4 \pm 3.1$ & $29.6 \pm 3.0$ & $63.1 \pm 6.5$ \\
\hline Liver & $61.3 \pm 0.8$ & $46.6 \pm 2.7$ & $29.0 \pm 1.9$ \\
\hline Ovary & $72.6 \pm 0.8$ & $17.0 \pm 2.1$ & $69.0 \pm 2.0$ \\
\hline \multicolumn{4}{|l|}{ 125-ICP Myristate+ } \\
\hline Adrenal cortex & $77.2 \pm 1.9$ & $26.4 \pm 2.8$ & $53.8 \pm 7.2$ \\
\hline Plasma & $56.5 \pm 5.0$ & $22.5 \pm 0.7$ & $36.2 \pm 0.5$ \\
\hline Liver & $81.2 \pm 1.5$ & $55.1 \pm 2.2$ & $32.7 \pm 3.1$ \\
\hline Ovary & $83.5 \pm 1.1$ & $23.5 \pm 1.8$ & $45.2 \pm 1.4$ \\
\hline \multicolumn{4}{|l|}{ 125-ICO Tween } \\
\hline Adrenal cortex & $90.9 \pm 1.8$ & $13.8 \pm 1.0$ & $68.5 \pm 5.2$ \\
\hline Blood & $69.4 \pm 3.7$ & $51.5 \pm 1.5$ & $34.6 \pm 1.6$ \\
\hline Liver & $78.5 \pm 1.8$ & $55.4 \pm 4.9$ & $27.4 \pm 6.6$ \\
\hline Ovary & $91.4 \pm 0.7$ & $43.0 \pm 2.9$ & $43.8 \pm 0.6$ \\
\hline \multicolumn{4}{|l|}{ 125-ICO Myristate } \\
\hline Adrenal cortex & $86.8 \pm 1.3$ & $22.2 \pm 4.3$ & $62.9 \pm 0.8$ \\
\hline Blood & $56.9 \pm 3.6$ & $71.9 \pm 1.1$ & $21.6 \pm 0.8$ \\
\hline Liver & $82.3 \pm 0.7$ & $35.3 \pm 2.0$ & $46.8 \pm 4.9$ \\
\hline Ovary & $83.2 \pm 3.0$ & $32.2 \pm 8.3$ & $46.7 \pm 3.7$ \\
\hline
\end{tabular}

* Values represent mean \pm SEM. $n=3,4$ or 5 .

$\dagger$ Tween vehicle $(1.6 \%$ tween 80 and $10 \%$ ethanol in saline).

$\ddagger$ Myristate vehicle (Isopropyl myristate-ethanol, 1:5, v/v).

$125-$ ICP $=125$-I-19-iodocholesteryl palmitate.

125-IC = 125-I-19-iodocholesteryl oleate. 
TABLE 3. Results of TLC analysis of lipid-soluble radioactivity from tissues of rats that received 125-ICP; separation of esters by degree of fatty acid saturation

\begin{tabular}{lccccc}
\hline & \multicolumn{4}{c}{$\%$ of Total radioactivity on plate present in each band* } \\
\cline { 2 - 5 } \multicolumn{1}{c}{ Tissue } & Origin & Arach & Linol & Oleate & Palm \\
\hline Adrenal cortex & 17.0 & 13.4 & 2.5 & 2.8 & 3.9 \\
Plasma & 30.0 & 9.1 & 10.7 & 2.4 & 1.4 \\
Liver & 67.5 & 3.4 & 2.3 & 2.0 & 2.5 \\
Ovary & 44.4 & 13.4 & 7.9 & 4.2 & 15.1 \\
125-ICP control & 2.9 & 2.0 & 2.2 & 22.2 & 64.3 \\
\hline
\end{tabular}

$125-\mathrm{ICP}=125-\mathrm{I}-19$-iodocholesteryl palmitate administered in the tween vehicle $(1.6 \%$ tween 80 and $10 \%$ ethanol in saline).

* Bands named according to migration of TLC standards.

Origin-Free cholesterol, highly unsaturated esters and other polar metabolites.

Arach-Cholesteryl arachidonate.

Linol-Cholesteryl and 19-iodocholesteryl linoleate.

Oleate-Cholesteryl and 19-iodocholesteryl oleate.

Palm - Cholesteryl and 19-iodocholesteryl palmitate.

radioactivity comigrated with standards containing unsaturated fatty acids. This suggests that when the 125-ICP was injected, there was hydrolysis of the ester and reesterification with a different fatty acid. This has also been reported to be the case when $7 \alpha-{ }^{3} \mathrm{H}$ cholesterol $1{ }^{14} \mathrm{C}$-palmitate was injected in man. ${ }^{(6)}$ The sites for this hydrolysis and reesterification have yet to be defined.

Based on these and other studies concerning the disposition of administered cholesterol and cholesterol ester, the vehicle used for administration can influence the results in at least two ways. First, the detergent action of the tween vehicle facilitates not only the solubility of cholesterol derivatives in plasma, but also their incorporation into lipoproteins for subsequent transport to target tissues. The absence of such a solubilizing component in the myristate vehicle may result in precipitation of these lipophilic agents from solution when injected into the blood. Precipitated material would be expected to become entrapped in the capillaries of the lung. Although samples of lung were taken only when 125-ICP was injected, radioactivity in the lung was greater when myristate was used as the vehicle for administration.

Secondly, it is currently unknown whether it is essential for cholesterol esters to be hydrolyzed to free cholesterol prior to uptake by steroid synthesizing tissues such as adrenal and ovary. DeXTER et al..$^{(7)}$ have shown that nonesterified plasma cholesterol is more efficiently incorporated into adrenal tissue than plasma cholesterol palmitate, and this is consistent with our findings with 125-IC and 125-ICP. If hydrolysis of the esters to free 125-IC is an important factor in tissue uptake, the physical state of the administered esters could be critical. For example, Vahouny et al. ${ }^{(8)}$ have previously shown that cholesterol oleate in micellar form is rapidly hydrolyzed by pancreatic juice cholesterol esterase, whereas albumin-stabilized cholesterol oleate is a very poor substrate for this enzyme. Administration of 125 -ICO in myristate could have a similar retarding effect on the subsequent hydrolysis to free 125-IC.

Based on the results of the tissue distribution studies, 125-ICO in the tween vehicle was used in an attempt to image the rat adrenal gland. At the 1 day interval, an area of activity thought to represent the right adrenal was evident. The left adrenal, however, was not resolved because of a large area of activity associated with the spleen. At 5 days, however, the adrenals and the thyroid were clearly evident. The levels of radioactivity $\left(\%\right.$ Administered Dose $\mathrm{g}$ tissue $\left.{ }^{-1}\right)$ for selected tissues of this rat at 5 day post injection were: adrenal cortex-7.858, blood-0.018, kidney-0.025, liver-0.141, ovary-1.286, spleen- -0.031 and thyroid-193.104. 


\section{Conclusions}

1. The tissue distribution profiles of 125-IC, $125-\mathrm{ICO}$ and 125-ICP were affected by the injection vehicle used. The myristate vehicle is unsuitable for achieving target tissue selectivity of 125 -IC and its esters.

2. Both 125-ICO and 125-ICP showed selective concentration of radioactivity in the adrenal cortex when administered in the tween vehicle with 125 -ICO showing greater predilection than 125 -ICP.

3. Injection of $125-\mathrm{ICO}$ in the tween vehicle resulted in a concentration of radioactivity in the adrenal cortex sufficient to afford a positive image at 5 days post injection when the rat was scanned with a small animal scanner.

4. 125-ICP was hydrolyzed and reesterified with unsaturated fatty acids in vivo.

Acknowledgements-This research was supported by grant CA-08349 awarded by the National Cancer Institute, U.S.P.H.S. The authors wish to acknowledge the technical assistance of Miss Sandra Swayze and Mr Anthony Buswink. Stable 19-iodocholesterol was kindly provided by Searle Laboratories, Skokie. Illinois.

\section{References}

1. Counsell R. E., Ranade V. V., Kulkarni P. G. and Afiatpour P. J. nucl. Med. 14, 777 (1973).

2. Fukushi K., IrIE T., Nozaki T., Ido T. and Kasido Y. J. lab. Comp. Radiopharm. XVI 49 (1979) abst.

3. Nordblom G. D., Schappa L. W.. Floyd E. E., Langdon R. B. and Counsell R. E. J. steroid Biochem. 13, 463 (1980).

4. Korn N., Nordblom G. D., Floyd E. E. and Counsell R. E. J. Pharm. Sci. 69, 1014 (1980).

5. GoOdman D. S. Physiol Rev. 45, 747 (1965).

6. Rosenfeld R. S., Zumoff B. and Hellman L. Atherosclerosis 13, 77 (1971).

7. Dexter R. N., Fishman L. M. and Ney R. L. Endocrinology 87, 836 (1970).

8. Vahouny G. V., Borja C. R. and Treadweli C. R. Archs Biochem. Biophys. 106, 440 (1964). 